\title{
Bilateral closed posterior ankle dislocation without fracture in a professional footballer: an unusual case report and literature review
}

\author{
Jean Marie Vianney Hope ${ }^{1 *}$, Jean Paul Bitega ${ }^{2}$, Francis Mugabo ${ }^{3}$, Edmond Mukimbili ${ }^{4}$, and Albert Ndata ${ }^{5}$ \\ 'Department of Orthopedics and Traumatology, Orthopedic and Spinal Surgeon, Rwanda Military Hospital, Kigali-Rwanda. \\ ${ }^{2}$ Department of Orthopedics and Traumatology, Orthopedic Surgeon, Rwanda Military Hospital, Kigali-Rwanda. \\ ${ }^{3}$ Department of Orthopedics and Traumatology, Orthopedic Surgeon, Rwanda Military Hospital, Kigali-Rwanda. \\ ${ }^{4}$ Department of Orthopedics and Traumatology, Orthopedic Surgeon, Rwanda Military Hospital, Kigali-Rwanda. \\ ${ }^{5}$ Post Graduate in Orthopedics and Traumatology, Rwanda Military Hospital.
}

*Address for Correspondence: Dr Jean Marie Vianney Hope, Department of Orthopedics and Traumatology, Orthopedic and Spinal Surgeon, FWACS (fellow West African College of Surgeons), Rwanda Military Hospital, P.O. Box: 3377 Kigali-Rwanda, Mob: +250789364492; E mail: hopejmv@gmail.com

Received: 21 July 2020; Accepted: 07 August 2020; Published: 10 August 2020

Citation of this article: Vianney Hope JM, Bitega JP, Mugabo F, Mukimbili E, Ndata A (2020) Bilateral closed posterior ankle dislocation without fracture in a professional footballer: an unusual case report and literature review. Rea Int J of Clin med Case Rep. 1(1): 004-008. DOI: 10.37179/rijcmcr.000002.

Copyright: (C) 2020 Vianney Hope JM, et al. This is an open access article distributed under the Creative Commons Attribution License, which permits unrestricted use, distribution, and reproduction in any medium, provided the original work is properly cited.

\begin{abstract}
Ankle dislocation is total loss of contact between the articular surfaces of the talus and the ankle mortise. It occurs following violent high-energy trauma and is often associated with fractures. As ankle dislocation without associated fracture is rare, bilateral involvement is extremely rare.

We report clinical and radiological features, treatment principles and long-term outcome of a 26-year-old professional footballer who sustained a bilateral closed posterior ankle dislocation without fracture during sport accident. He was treated by closed reduction under fluoroscopy guidance and immobilization with bilateral below knee plaster casts for six weeks. After removal of the casts, intensive rehabilitation program was initiated. He has made an uneventful recovery and returned to play at competitive level 8 months after injury.

Keywords: Ankle dislocation without fracture, High-energy trauma, Sport accident.
\end{abstract}

\section{Introduction}

Ankle dislocation refers to the total loss of contact between the normal articular surfaces of the talus and the ankle mortise and is almost always associated with malleolar fractures and rupture of the distal Tibio-fibular syndesmosis. Due to the violence of the causative high-energy trauma, there are often associated soft tissue lesions [1, 2].
Thus, ankle dislocation without associated fractures or pure ankle dislocation is a rare entity, and about 150 cases have been reported in the literature [3-7]. However, only one case with bilateral involvement has been reported to date [8]. Various patterns of pure ankle dislocation exist. Depending on the type of displacement, the postero-medial type is the most common.

In posterior ankle dislocation without fracture, the talus is out of 
Citation: Vianney Hope JM, Bitega JP, Mugabo F, Mukimbili E, Ndata A (2020) Bilateral closed posterior ankle dislocation without fracture in a professional footballer: an unusual case report and literature review. Rea Int J of Clin med Case Rep 1(1): 004-008. DOI: 10.37179/rijcmcr.000002.

the ankle mortise and along with other bones of the foot displaced posteriorly with intact ankle mortise as well as malleoli and distal Tibio-fibular syndesmosis [9-12].

Regarding the grade of soft tissue injury, ankle dislocation may be closed or open [13-17]. We report the second case of bilateral closed posterior ankle dislocation without fracture in a 26-yearold professional footballer. Our aim was to highlight clinical and radiological features, treatment principles and long-term outcome.

\section{Case Report}

A 26-year-old professional footballer who has been playing football at the competitive level for the last 8 years was received to the Accident and Emergency department one hour after sport accident. He falls with both feet in inversion position during a competitive football match. He reports an episode of previous trauma on his ankles which did not prevent him playing.

On general physical examination, he was lying in a stretcher; healthy appearing but in severe pain; alert and oriented to person, place and time; responds appropriately; in no acute distress and his general status was conserved. Blood pressure measurement revealed a pressure of $125 / 70 \mathrm{mmHg}$, his pulse rate was 85 beats/minute, his respiratory rate was 23 cycles/minute and his body mass index were 27. On inspection of both ankles, there were deformity and swelling. No skin lesions were detected (Figure 1).

Palpation and active mobilization of ankles were painful. Dorsalis Pedis and posterior tibialis pulses were easily palpated. The systemic review was unremarkable.

Anteroposterior (AP) and lateral radiographs of both ankles showed bilateral posterior ankle dislocation without associated fractures (Figure 2). Blood examination revealed WBC $7700 / \mu \mathrm{l}$ and $\mathrm{Hb} 13.5 \mathrm{~g} / \mathrm{dl}$. The arteriovenous Doppler ultrasound of both lower limbs was normal. Magnetic Resonance Imaging (MRI) of both ankles was normal without any Musculo-ligamentous injury. Thus, emergency closed reduction was planned. Under loco-regional anesthesia (femoral block) and C-arm guidance, anatomical reduction of both ankles was achieved.

The patient was thereafter immobilized with bilateral below knee plaster casts. Control radiographs were satisfactory (Figure 3). The patient was immobilized for 6 weeks. He was on daily doses of anticoagulation therapy during the time of immobilization. He was scheduled for intensive physiotherapy immediately after plaster cast removal and regular monthly follow up. He made an uneventful recovery and he returned to play at competitive level after 8 months.

At 3-year-follow up, he was pain-free and playing regularly in his team. Functional outcome was excellent with Gay and Evrard score of $15 / 15$. Range of motion (ROM) of both ankles was $25^{\circ}$ of dorsiflexion; $45^{\circ}$ of plantarflexion; $15^{\circ}$ of abduction; $20^{\circ}$ of adduction; $50^{\circ}$ of internal rotation (supination) and $25^{\circ}$ of external rotation (pronation) bilaterally (Figure 4). Control MRI (Figure 5) and radiographs (Figure 6) were unremarkable, no signs of ankle osteoarthritis or avascular necrosis of the talus.

\section{Discussion}

Ankle dislocation without fracture (or pure ankle dislocation) is rare and extraordinarily little has been written about this lesion.
Less than 150 cases have been reported in the literature [6, 7, 18-20]. Bilateral involvement is extremely rare at the extent that only one case with bilateral ankle dislocation without fracture has been reported [8].

We attribute the rarity of this lesion to the mechanical stability of the Tibio-Fibular mortise and the resistance of ankle collateral ligaments which are as strong as malleoli, and this explains the high incidence of fractures $[19,21]$. They may occur at any age with male gender preponderance $[6,17,22]$. In our Center over a 3-year-period, we have in our trauma registry 471 ankle injuries excluding sprains and contusions. There were 322 cases $(68.3 \%)$ of malleolar fractures; 139 cases $(29.6 \%)$ of ankle fracture dislocation; 9 cases $(1.9 \%)$ of subtalar dislocations and only 1 case $(0.2 \%)$ of bilateral ankle dislocation without fracture. The age of our patient was 26 years.

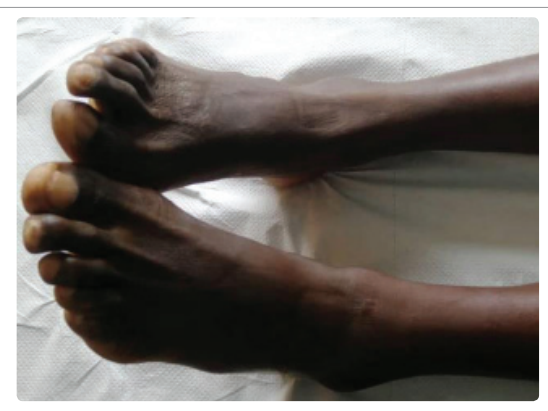

Figure 1: Clinical image of both ankles on arrival showing swelling and deformity.

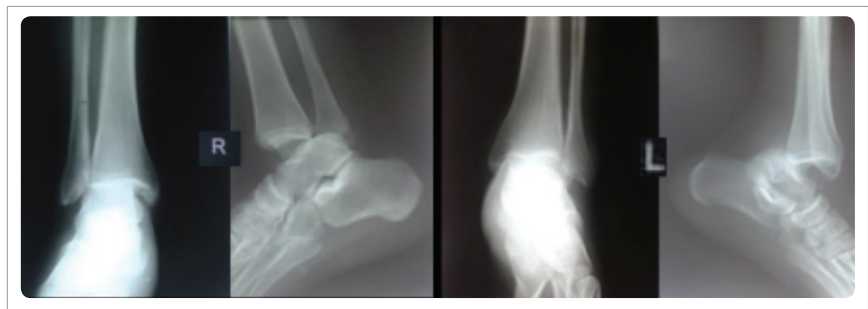

Figure 2: Radiographs of right $(R)$ and left $(L)$ ankles showing bilateral posterior dislocation without associated fractures. There are loss of interarticular surface and loss of height of lateral malleolus (AP view) as well as posterior displacement of the talus along with other bones of the foot (lateral view). Medial and lateral malleoli are intact.

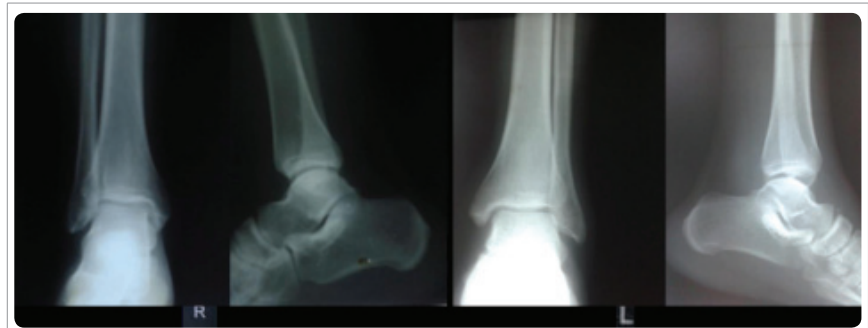

Figure 3: Immediate postoperative control radiographs of the right $(R)$ and left $(\mathrm{L})$ ankles showing anatomical reduction. In the AP views: the distal fibula is slightly superimposed on the tibia; the lateral malleolus is longer than the medial malleolus; the tibiotalar space is open and the mortise is uniformly visible. In the lateral views: the distal fibula is superimposed by the posterior part of the distal tibia; the talar dome is superimposed and the joint space between the tibia and the talus is uniform. 

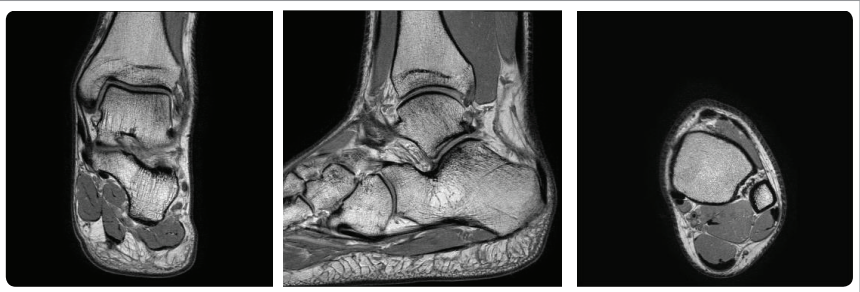

Figure 4: At 3-year-follow up, clinical images showing normal full range of motion of both ankles.

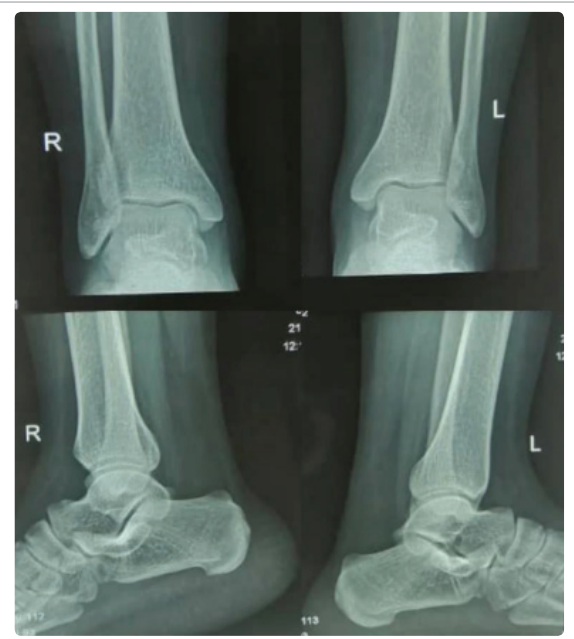

Figure 5: Coronal, sagittal and axial T2-wighed MRI scans showing norma ankle joints without ligamental injuries.

Ankle dislocation without fracture occurs following violent highenergy trauma $[21,24]$.

The most frequent causes of injury are traffic collision; followed by contact sport accident (football, rugby, basketball, volleyball) and fall from height $[6,8,11,16,19,21,23,24]$.

In our case, the cause of injury was sport accident (football). According to Fernandez, the mechanism of injury is a high-energy trauma that produces a sufficient anteroposterior force which when applied to the foot with ankle joint in maximal plantarflexion provokes a posterior dislocation of the ankle.

The plantarflexion is considered as unstable position of the Tibiotalar joint because during this position, the thinner part of the talar body is within the mortise which increases the risk of dislocation [25]. In our case, unexpected violent fall from a certain height when both ankles were in inversion position (combination of plantarflexion, adduction and supination movements) is believed to be responsible for bilateral ankle dislocation without fracture.

Fahey and Murphy have classified ankle dislocation without fracture in 5 subtypes depending on the direction of displacement: anterior, posterior, medial, lateral and superior [21, 26-29]. However, association patterns may be found in some cases, and the posteromedial ankle dislocation is the most frequent subtype [14, 24, 30, 31]. Our case was a posterior subtype bilaterally.

The factors predisposing to the ankle dislocation without fracture are ligamentous laxity, loss of height of internal malleolus, inadequate covering of the talus, previous ankle sprains and weakness of fibular muscles $[22,24]$. Hyperlaxity has been reported in 2 cases in the series of 16 patients by Elise et al and in 2 cases in a series of 8 patients by Colville et al, [10, 24].

Thangarajah has reported a case of bilateral ankle dislocation without fracture in patient who had ligamentous laxity [8]. The loss of height of internal malleolus is calculated by the proportion between the height of internal malleolus and external malleolus (Elisé Index) on AP radiography of the ankle. Its normal value ranges from 0.58 to 0.62 . This loss of height of internal malleolus has been reported by some investigators $[15,24,27]$.

However, the tibial coverage on the talus is normal in all reported cases. It is no longer considered as a risk factor of ankle dislocation without fracture $[7,15,24,28]$. In our case, as the patient is a professional footballer who has been playing football at the competitive level for the last 8 years, we attribute the bilateral ankle dislocation without fracture to unrecognized multiple mild sprains (micro-traumas) which he may had previously during training or competitive matches. No loss of height of internal malleolus was noted.

Often, soft tissue injuries (skin, capsulo-ligamentous, vascular, nerve and Musculo-tendinous) are frequent in ankle dislocation without associated fractures. Skin injuries arise up to $50 \%$ of cases and their locations depend on the severity of the trauma and the direction of displacement. They predispose to ankle arthritis [10, 1317, 24]. In our case, no skin lesion was noted.

For the dislocation to occur, the articular capsule is always thorn [24]. The ligamental injury is almost always present and concerns the lateral collateral ligament in most of the time, and less commonly the medial collateral ligament or both [10]. The distal Tibio-fibular ligaments are intact in the posterior ankle dislocation without associated fractures $[2,10]$.

The anterior tibial artery is the most injured $[24,30]$. The Pedis artery and saphenous vein may also be injured [22, 32]. These lesions range from rupture to contusion with high risk of intimal injury which could lead to thrombosis. Three cases of below knee amputation following vascular injury in pure ankle dislocation have been reported [2, 4, 33]. In our case, we perform an arteriovenous Doppler ultrasound of both lower limbs to rule out any vascular injury.

The nerve injuries are less common in pure ankle dislocation and, if they occur, they are represented by elongation or rupture. They are reported in 5 cases in a review of 73 cases [30]. Elisé et al, have found parenthesis and dysesthesias in the dermatomal distribution of the deep and superficial fibular nerves respectively in 2 patients each [24]. The incidence of neurovascular injuries is reported to be $10 \%$ [34]. The rarity of these injuries is due to the rupture of their attachments in high energy trauma, leaving them free [35]. Musculo-tendinous injury is not well highlighted in case of closed dislocation [24]. It can be the rupture of anterior tibialis, extensor hallucis longus and extensor digitorum longus muscles $[4,22,24,32]$. One case of rupture of flexor hallucis longus muscle has been reported [29].

In our case, no muscle rupture was detected. The management of ankle dislocation without fracture should not be delayed because it is an extreme emergency $[11,14,16]$. Closed dislocations are 
Citation: Vianney Hope JM, Bitega JP, Mugabo F, Mukimbili E, Ndata A (2020) Bilateral closed posterior ankle dislocation without fracture in a professional footballer: an unusual case report and literature review. Rea Int J of Clin med Case Rep 1(1): 004-008. DOI: 10.37179/rijcmcr.000002.

treated orthopedically. Under anesthesia, knee flexed at $90^{\circ}$ to relax the triceps surae muscle, anatomic reduction is achieved under fluoroscopic guidance, then the leg is immobilized with a below knee plaster cast for 6 to 8 weeks [24, 36-39].

Open dislocations require extensive debridement, soft tissue repair with tetanus toxoid and broad-spectrum antibiotics [20,34, 40]. The repair of collateral ligament is controversial. Fink Meier et al recommended their repair only in case of ankle instability [36]. Other authors suggest their repair in all open dislocations $[2,24,30]$. In our case, we performed a closed reduction and immobilization with a below knee plaster cast for 6 weeks.

Elisé et al have found 6 excellent; 4 good and 1 poor outcome in a series of 11 patients at 11-year-follow up. Their complications were ankle stiffness, parenthesis and trophic disorders [24]. Garbuio et al have reported 5 cases of ankle osteoarthritis [30]. One case of avascular necrosis of the talus has been reported by Toohey [34].

Residual ligamentous laxity is rare and Colville et al have reported one case [10]. Functional outcome was excellent in our patient at 3 -year follow up. The Gay and Evrard score was 15/15. No signs of ankle arthritis or avascular necrosis of the talus were seen on control radiographs. He was satisfied and had returned to his full-time employment.

\section{Conclusion}

Bilateral closed posterior ankle dislocation without fracture is an exceptional rare clinical condition occurring following high-energy trauma. Its rarity is due to the mechanical stability of the ankle mortise and the resistance of the collateral ligaments which are as strong as malleoli, explaining the high incidence of fractures. In the absence of complications, orthopedic treatment with below knee plaster casts gives satisfactory results. Based on this deficiency in the literature, this case displays awareness to physicians in the case of ankle injuries following high-energy trauma.

\section{Conflicts of Interest}

No competing interests declared.

\section{Funding}

No benefits in any form have been received or will be received from a commercial party related directly or indirectly to the subject of this article.

\section{Ethical Approval}

This article does not contain any studies with human participants or animals performed by any of the authors.

\section{Informed Consent}

Written informed consent was obtained from the patient to publish the information, including her photographs.

\section{Authors' Contributions}

All authors have participated equally in the present study.

\section{References}

1. Alireza S, Afshin Z (2007) Neglected ankle dislocation. The journal of foot and ankle surgery 46: 307-309. Link: https://bit.ly/3acjhYB
2. Mohering HD, Tan RT, Marder RA, Lian G (1994) Ankle dislocation. J Orthop Trauma 8: 167-172. Link: https://bit.ly/2F0Gr8S

3. Jiménez-Martín A, López-Vidriero-Tejedor E, González-Herranz J (2008) Fracture-free ankle dislocations: four cases. Rev Esp Cir Ortop Traumatol. 52: 105-109.

4. Kelly PJ, Peterson LFA (1962) Compound dislocation of the ankle without fracture. Am J Surg 103: 170-172. Link: https://bit. ly/3aaeTcM

5. Kiefer EA, Wikstrom EA, McDonald JD (2006) Ankle dislocation without fracture: an on-field perspective. Clin J Sport Med 16: 269270. Link: https://bit.ly/2CcpEP9

6. Larsen J, Burzotta J, Brunetti V (1998) Ankle Dislocation without Fracture in a Young Athlete. J Foot Ankle Surg 37: 334-338. Link: https://bit.ly/2CcpEP9

7. Rivera F, Bertone C, De Martino M, Pietrobono D, Ghisellini F (2001) Pure dislocation of the ankle: three case reports and literature review. Clin Orthop Relat Res 382: 179-184. Link: https://bit.ly/3fDKyEA

8. Thangarajah T, Giotakis N, Matovu E (2008) Bilateral ankle dislocation without malleolar Fracture. J Foot Ankle Surg 47: 441-446. Link: https://bit.ly/3iqGM36

9. Alami M, Bassir R, Mahfoud M, Lamrani MO, Elbardouni E, et al. (2010) Upward tibiotalar dislocation without fracture: A case report. Foot 20: 149-150. Link: https://bit.ly/3isSv10

10. Colville MR, Colville JM, Manoli A (1987) Posteromedial dislocation of the ankle without fracture. J Bone Joint Surg 69: 706-710. Link: https://bit.ly/2DOILiK

11. Georgilas I, Mouzopoulos G (2008) Anterior ankle dislocation without associated fracture. A case with an 11-year follow-up. Acta Orthop Belg 74: 266-269. Link: https://bit.ly/2DJDh8Z

12. Kaneko K, Mogami A, Maruyama Y, Shimamura Y, Yamaguchi T (2000) Posterolateral dislocation of the ankle without fracture. Injury 31: 740-743. Link: https://bit.ly/33FFk93

13. Agrawal AC, Raza HKT, Haq RU (2008) Closed posterior dislocation of the ankle without fracture. Indian J Orthop 42: 360-362. Link: https:// bit.ly/2PBxwgn

14. Lazarettos I, Brilakis E, Efstathopoulos N (2013) Open Ankle Dislocation without Associated Malleolar Fracture. J Foot Ankle Surg 52: 508-512. Link: https://bit.ly/3gHMAFa

15. Tarantino U, Cannata G, Gasbarra E, Bondi L, Celi M, et al. (2008) Open medial dislocation of the ankle without fracture. J Bone Joint Surg Br 90: 1382-1384. Link: https://bit.ly/3anfjgd

16. Uyar M, Tan A, Isler M, Cetinus E (2004) Closed posteromedial dislocation of the tibiotalar joint without fracture. Br J Sports Med 38: 342-343. Link: https://bit.ly/33Lg954

17. Yurttaş Y, Kilinçoğlu V, Toker S, Kürklü M, Atilla A, et al. (2009) Closed posteromedial dislocation of ankle in a 12-year-old boy: a case report. Cases J 2: 6550. Link: https://bit.ly/31yVlel

18. Scott JE (1974) Dislocations of the ankle without fracture. Injury 6: 63-66. Link: https://bit.ly/30GNufh 
Citation: Vianney Hope JM, Bitega JP, Mugabo F, Mukimbili E, Ndata A (2020) Bilateral closed posterior ankle dislocation without fracture in a professional footballer: an unusual case report and literature review. Rea Int J of Clin med Case Rep 1(1): 004-008. DOI: 10.37179/rijcmcr.000002.

19. Wilson MJ, Michele AA, Jacobson EW (1939) Ankle dislocations without fracture. J Bone Joint Surg. 21: 198-204. Link: https://bit. ly/2DDvNob

20.Wroble RR, Nepola JV, Malvitz TA (1988) Ankle dislocation without fracture. Foot Ankle. 9: 64-74. Link: https://bit.ly/31AJSuK

21. Fahey JJ, Murphy JL (1965) Dislocations and fractures of the talus. Surg Clin North Am. 45: 79-102. Link: https://bit.ly/31yNCNe

22. Prost à la Denise J, Tabib W, Pauthier F (2009) Long-term result of a pure tibiotalar dislocation in a child. Orthop Traumatol Surg Res 95: 558-562. Link: https://bit.ly/3kvVgRi

23. Dahmani O, Ouchrif Y, Alarab H, Blanc S, Elmrini A (2014) Pure ankle dislocation in a footballer: A case report and literature review. J Traumatol Sport 31: 224-227.

24.Elisé S, Maynou C, Mestdagh H, Forgeois P, Labourdette P (1998) Ankle dislocation without fractures: a series of 16 cases. Acta Orthop Belg 64: 1. Link: https://bit.ly/33Ky8Za

25. Fernandes TJ (1976) The mechanism of talo-tibial dislocation without fracture. J Bone Joint Surg Br. 58: 364-365. Link: https://bit. ly/3fMNWNo

26. Lamraski G, Clegg E (2010) Unusual upward closed tibiotalar dislocation without fracture: A case report. Foot Ankle Surg 16: 44-46. Link: https://bit.ly/33JMGZh

27. Lui TH, Chan KB (2012) Posteromedial ankle dislocation without malleolar fracture: A report of six cases. Injury 43: 1953-1957. Link: https://bit.ly/33IwNCj

28. Wang YT, Wu XT, Chen H (2013) Pure closed posteromedial dislocation of the tibiotalar joint without fracture. Orthop Surg 5: 214-218. Link: https://bit.ly/2F6pREF

29. Wehner J, Lorenz M (1990) Lateral ankle dislocation without fracture. J Orthop Trauma. 4: 362-365. Link: https://bit.ly/2DOHHvq

30. Garbuio P, Gérard F, Gagneux E (1995) Ankle dislocation without fractures: a series of 9 cases. Rev Chir Orthop 81: 601-608. Link: https://bit.ly/33Ihfye
31. Marsh JL, Slongo TF, Agel J, Broderick JS, Creevey W, et al. (2007) Fracture and dislocation classification compendium - 2007: Orthopaedic Trauma Association classification, database and outcomes committee. J Orthop Trauma 21: S1-128. Link: https://bit. ly/30JsR2o

32. Tsatedem FA, Tsiagadigui JG, Ndando RP, Arabo MS, Bayiha A, et al. (2012) [Decision of amputation in the initial management of severe open dislocation of the ankle about a case observed in Douala Laquintinie Hospital following an accident by motorcycle taxi]. Pan Afr Med J 13: 73. Link: https://bit.ly/2XLA1Bk

33. Tondeur G, Dufaz JP, Nemry CH (1964) Ankle dislocation without fractures: Two case report. Act Orthop Belg 30: 410-414.

34. Toohey JS, Worsing Jr RA (1989) A long-term follow-up study of tibiotalar dislocations without associated fractures. Clin Orthop Relat Res 239: 207-210. Link: https://bit.ly/2Cf02RL

35. De Mourgues G, Comtet JJ, Leclerc-Chalvet F (1969) Ankle dislocation without associated fractures: a case report and literature review. Lyon Chir 65: 661-667. Link: https://bit.ly/2XLnuxL

36. Finkemeier C, Engebretsen L, Gannon J (1995) Tibial-talar dislocation without fracture: treatment principles and outcome Knee Surg Sports Traumatol Arthrosc 3: 47-49. Link: https://bit.ly/30IoowD

37. Karampinas PK, Stathopoulos IP, Vlamis J, Polyzois VD, Pneumatikos SG (2012) Conservative treatment of an anterior-lateral ankle dislocation without an associated fracture in a diabetic patient: a case report. Diabet Foot Ankle 3:1-5. Link: https://bit.ly/33Jms8Z

38. Agoumi O, EL Mrini A, Boutayeb F (2006) Pure ankle dislocation: a case report and literature review. Méd. Chir. Pied 22: 30-31. Link: https://bit.ly/3ko1674

39.Zizah S, Benabid M, Mezzani A, Bennani A, Lahrach K, et al. (2012) A rare case of ankle dislocation without fracture. J Traumatol Sport. 29: 212-214. Link: https://bit.ly/3ko1674

40. Peraire M (1913) Open lateral ankle dislocation without fracture: A case report. Paris Chir 5: 959. Link: https://bit.ly/2PHguxs 